\title{
Effect of gas adsorption-induced pore radius and effective stress on shale gas permeability in slip flow: New Insights
}

https://doi.org/10.1515/geo-2019-0073

Received Apr 02, 2019; accepted Nov 05, 2019

\begin{abstract}
Shale, a heterogeneous and extremely complex gas reservoir, contains low porosity and ultra-Low permeability properties at different pore scales. Its flow behaviors are more complicated due to different forms of flow regimes under laboratory conditions. Flow regimes change with respect to pore scale variation resulting in change in gas permeability. This work presents new insights regarding the change of pore radius due to gas adsorption, effective stress and impact of both on shale gas permeability measurements in flow regimes. From this study, it was revealed that the value of Klinkenberg coefficient has been affected due to gas adsorption-induced pore radius thickness impacts and resulting change in gas permeability. The gas permeability measured from new proposed equation is provides better results as compare to existing equation. Adsorption parameters are the key factors that affect radius of shale pore. Both adsorption and effective stress have an effect on the pore radius and result gas permeability change. It was found that slip effect enhances the apparent gas permeability and also changes with effective stress; therefore, combine impact of slip flow and effective stress is very important as provides understanding in evolution of apparent permeability during shale gas production.
\end{abstract}

Keywords: Shale gas, Pore radius, Flow regimes, Effective stress, Gas permeability, and Gas adsorption

*Corresponding Author: Aifen Li: School of Petroleum Engineering, China University of Petroleum (East China), Huangdao district, Qingdao, Shangdong Province, China (266580);

Email: aifenli@upc.edu.cn, Tel.: +86-15154289972

Asadullah Memon, Wencheng Han, Weibing Tian: School of Petroleum Engineering, China University of Petroleum (East China), Huangdao district, Qingdao, Shangdong Province, China (266580)

\section{Abbreviations}

BET Brunauer-Emmett-Teller

D-A Dubinin- Astakhov

D-R Dubinin and Radushkevich

LBM Lattice Boltzmann method

\section{Nomenclature}

b Slip coefficient, $\mathrm{MPa}$

$\mathbf{b}_{\mathbf{k}}$ Klinkenberg coefficient

c Proportionally factor

D Parameter related to the pore structure

$\mathbf{K}_{\mathbf{a a p}}$ Gas apparent permeability, nd

$\mathbf{K}_{\mathbf{b}}$ Boltzmann constant, $\mathrm{J} / \mathrm{K}$

$\mathbf{K}_{\mathbf{g}}$ Gas permeability, nd

$\mathbf{K}_{\mathbf{0}}$ Absolute permeability, nd

$\mathbf{K}_{\mathbf{n}}$ Knudsen number, dimensionless

m Molecule mass

$\mathbf{n}_{\text {ex }}$ Excess gas adsorption capacity, $\mathrm{mmol} / \mathrm{g}$

$\mathbf{n}_{\mathbf{L}}$ Maximum absolute gas adsorption capacity of monolayer adsorption, $\mathrm{mmol} / \mathrm{g}$

$\mathbf{n}_{\mathbf{0}}$ Maximum absolute gas adsorption capacity of micropore- filling, $\mathrm{mmol} / \mathrm{g}$

P Equilibrium pressure, $\mathrm{MPa}$

P Gas pressure, Pascal

$\mathbf{P}_{\mathbf{c}}$ Confining pressure, $\mathrm{MPa}$

$\mathbf{P}_{\mathbf{L}}$ Langmuir pressure, $\mathrm{MPa}$

$\mathbf{P}_{\mathbf{m}}$ Mean gas pressure, $\mathrm{MPa}$

$\mathbf{P}_{\mathbf{0}}$ Saturation vapor pressure, $\mathrm{MPa}$

$\mathbf{P}_{\mathbf{p}}$ Pore pressure, $\mathrm{MPa}$

$r$ Pore radius, $\mathrm{m}$

r_cor Gas adsorption-induced pore radius, $\mathrm{m}$

SSA Specific surface area, $\mathrm{m}^{2} / \mathrm{g}$

TOC Total organic carbon, $\%$

V Amount of adsorbed gas or absolute gas adsorption

$\mathbf{V}_{\mathbf{0}}$ Volume of micro-pores or maximum sorption capacity

$\mathbf{W}_{\mathbf{0}}$ Gas sorption capacity, $\mathrm{mmol} / \mathrm{g}$ 
$\boldsymbol{\rho}_{\mathrm{a}}$ Density of adsorbed gas, $\mathrm{g} / \mathrm{cm}^{3}$

$\boldsymbol{\rho}_{\mathrm{f}}$ Density of free gas, $\mathrm{g} / \mathrm{cm}^{3}$

$\boldsymbol{\mu}$ Gas viscosity, $\mathrm{cp}$

\section{Greek symbols}

$\boldsymbol{\alpha}_{\mathbf{k}}$ Adjustable parameter related to pore compressibility

$\zeta_{\mathbf{o}}$ An asymptotic limit value

$\boldsymbol{\sigma}$ Collision diameter, $\mathrm{m}$

$\zeta$ Dimensionless rarefaction coefficient

$\boldsymbol{\alpha}$ Effective stress coefficient, MPa

$\boldsymbol{\delta}_{\mathbf{m}}$ Gas molecule collision diameter, $\mathrm{m}$

\section{Introduction}

Shale gas reservoirs are important source of energy after discovery of huge reserves of such reservoir around the world. Flow regime is a key parameter of shale flow mechanisms and is a function of three important parameters such as pressure, fluid type and pore size. Pore size/radius may be affected due to multiple parameters such as adsorption/desorption, water saturation (multiphase flow), fractures, and creep. These parameters are potentially impact on flow regimes and affiliated parameters such as porosity and permeability [1].

In shale, the gas flow is affected by the pore scales such as macroscale, mesoscale, microscale and nanoscale and due to this reason the various flow regimes are identified in pore network models. Generally, gas is first desorbing from the pore wall of the kerogen and move towards matrix system and secondly, flux transfer arises among the matrix and fracture system due to pressure gradient and at the end gas is being reached at the well bore and eventually produced. The kerogen contains micropores and mesopores ( $<4-5 \mathrm{~nm}$ average pore size) and interconnected nanopores that provide active sites for gas adsorptions [2]. Diffusion type (molecular) and slip flow are the main components in the microscale whereas the Knudsen or slip flow and Darcy flow are predominant in mesoscale; hence Knudsen is significant in the scale and cannot be ignored [3]. At the macroscale (fractures), Darcy flow dominates but there exist some Knudsen flow. Further, storage mediums in these pores network models are also different such as on a micro level, adsorption dominates both in organic and inorganic matter, on a meso and macro level, free gas in the pores dominates; however, adsorption is still present in a limited amount [4].
Many researchers have been presented the permeability models such as Javadpour, 2009 [5] proposed that two mechanism such as slip flow and diffusion that are exist together, at the same time from matrix to fracture system for gas migration. Civan et al., 2011 [6] and SakhaeePour and Bryant, 2011 [7] presented an apparent permeability model by considering slippage factor in Knudsen diffusion for shale gas reservoirs. Shi et al., 2013 [8] has presented permeability model that describes the all flow regimes simultaneously. Zhang et al., 2015 [9] investigated the influence factors and transport mechanisms for shale gas reservoirs by using Lattice Boltzmann method (LBM). He revealed that net desorption, slippage and diffusion flow are highly sensitive to the pore scale. Later, many researchers had thought that flow regimes play a vital part in gas apparent permeability and due to this reason; they classified the various flow regimes by adopting Knudsen number. On this concept, so many $\mathrm{K}_{n}$-corrected permeability models have been made to examine the transient behaviors of shale gas reservoirs [10, 11]. Furthermore, some researchers have presented another apparent permeability models which is based as slip flow and diffusion flow exist together and connect to the apparent permeability with nanoscales. It has found from this study that slip flow may be appeared separately without diffusion flow consideration [12-17]. Further, the study of flow mechanisms is very sensitive and complicated in shale gas reservoirs. Flow regimes are changes with respect to pore scale variation and resulting change in gas permeability. Hence, flow regimes are a key parameter that affects the gas permeability of the shale gas reservoirs. Further, the mineralogical composition perform key part in gas permeability change specially clay which includes many components such as smectite, illite, chlorite and kaolinite [18]. It was also found from literature that due to effective stress, the shale gas permeability is mainly influenced by mineralogical composition i.e. as increases of clay content the permeability becomes more reactive in respect to effective stress [19]. Based on above literature, this study has focused on how the gas permeability has altered due to gas adsorption-induced pore radius in slip flow region and how the pore size, slip flow and effective stress impact on gas apparent permeability.

The work flow used to conduct this study is shown in Figure 1. First, slip flow mechanism has been considered and investigated the impact of change in pore radius due to gas adsorption on shale gas permeability measurements. Results obtained from Klinkenberg gas permeability model (equation 1) and new proposed gas permeability model (equation 20) was compared at different shale samples and gases (such as helium and methane). The Gas 
Table 1: Experimental measured gas permeability and fitting parameters of shale sample [21].

\begin{tabular}{|c|c|c|c|c|c|c|c|}
\hline $\begin{array}{l}\text { Sample } \\
\quad \#\end{array}$ & $\begin{array}{l}\text { Gas } \\
\text { type }\end{array}$ & $\begin{array}{l}\text { Temp, } \\
\mathrm{F}\end{array}$ & $\begin{array}{c}\text { TOC, } \\
\%\end{array}$ & $\begin{array}{l}\text { Pmean, } \\
\text { Psia }\end{array}$ & $\begin{array}{l}\text { Gas permeability }\left(\mathrm{K}_{\mathrm{g}}\right) \text {, } \\
\mathrm{nD} \text { from experiment }\end{array}$ & $\begin{array}{c}\text { Absolute gas } \\
\text { Permeability }\left(\mathrm{K}_{o}\right), \mathrm{nD} \\
\text { from fitting }\end{array}$ & $\begin{array}{l}\text { Pore radius }(r), \\
n m \text { from fitting }\end{array}$ \\
\hline \multirow{6}{*}{2} & \multirow{3}{*}{$\mathrm{He}$} & \multirow{6}{*}{230} & \multirow{6}{*}{8.52} & 114 & 195 & \multirow{3}{*}{70.3} & \multirow{3}{*}{50} \\
\hline & & & & 449 & 102 & & \\
\hline & & & & 964 & 85 & & \\
\hline & \multirow{3}{*}{$\mathrm{Ch}_{4}$} & & & 114 & 41 & \multirow{3}{*}{18.38} & \multirow{3}{*}{30} \\
\hline & & & & 464 & 24 & & \\
\hline & & & & 964 & 21 & & \\
\hline \multirow{10}{*}{5} & \multirow{4}{*}{$\mathrm{He}$} & \multirow{10}{*}{230} & \multirow{10}{*}{8.65} & 115 & 315 & \multirow{4}{*}{82.13} & \multirow{4}{*}{31} \\
\hline & & & & 463 & 162 & & \\
\hline & & & & 965 & 103 & & \\
\hline & & & & 1965 & 86 & & \\
\hline & \multirow{6}{*}{$\mathrm{Ch}_{4}$} & & & 115 & 85 & \multirow{6}{*}{27.65} & \multirow{6}{*}{12} \\
\hline & & & & 215 & 54 & & \\
\hline & & & & 465 & 38 & & \\
\hline & & & & 716 & 34 & & \\
\hline & & & & 966 & 30 & & \\
\hline & & & & 1969 & 26 & & \\
\hline
\end{tabular}

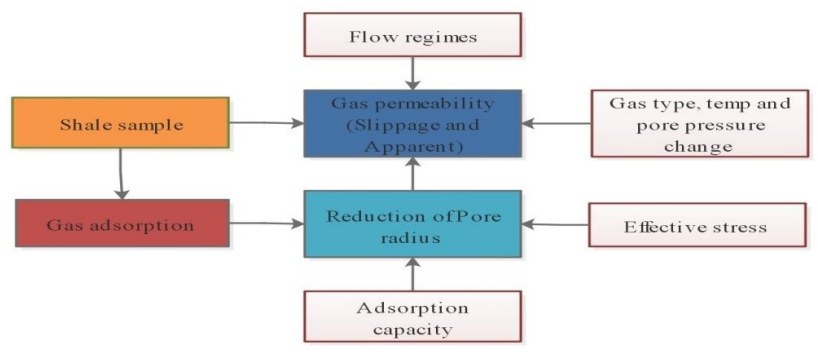

Figure 1: Work flow of present study.

adsorption model presented by Dubinin-Radushkevich (D$\mathrm{R})$ was adopted to measure the adsorbed layer thickness which impacts pore radius and gas permeability. This model was used generally because it considers the capillary condensation. Second, eight shale samples data were taken from literature and the effective role of key gas adsorption parameters such as total organic content (TOC), methane sorption capacity $\left(\mathrm{W}_{o}\right)$ and specific surface area (SSA) in pore radius variation was analyzed and also the relation of these parameters was observed at different shale samples containing high and low kerogen quality. Third, the impact of effective stress changes on pore radius was investigated. At the end, impacts of slip flow and effective stresses were combined for the development of shale gas apparent permeability.

\section{Sample and experimental descriptions}

The data of two samples of tight rocks such as shales were obtained from Sinha et al. (2013) [21] to conduct this study. Both samples have low porosity and organic content $<2 \%$ by weight. The gas permeability of these samples were measured through steady-state method at constant temperature, constant confining pressure and varying pore pressure. The experimental measured gas permeability and fitting parameters of shale samples are shown in Table 1.

\section{Model descriptions}

\subsection{Gas slippage permeability model}

Klinkenberg observed the occurrence of Knudsen flow in porous media which is so called Klinkenberg effect [22]. He showed that observed gas permeability is the function of mean gas pressure and proposed relation in between the measured gas permeability and absolute permeability of the porous medium is linearly on the basis of following 
Table 2: Identification of Knudsen number associated with flow regimes for shale.

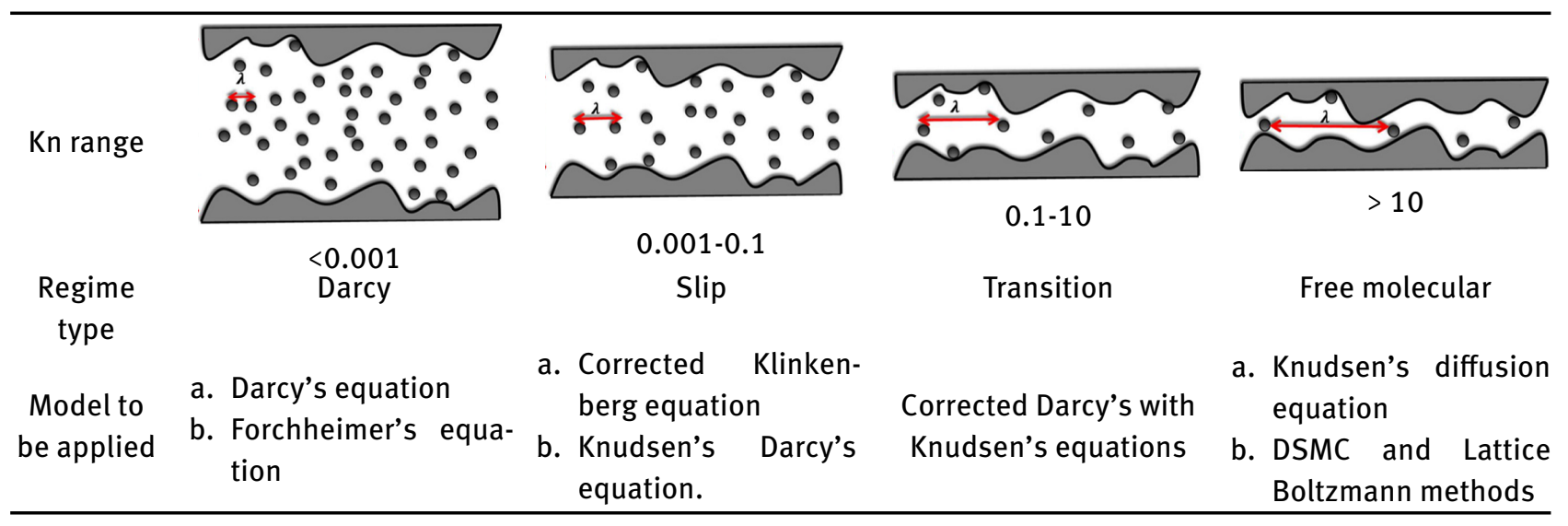

equation:

$$
K_{g}=K_{O}\left(1+\frac{b_{k}}{P_{m}}\right)
$$

where $K_{g}$ and $K_{o}$ is measured and absolute gas permeability in $\mathrm{nD}, P m$ is the mean gas pressure in psia and $b_{k}$ is the Klinkenberg coefficient, can be calculated through curve fitting technique and assumed as a constant. But $b_{k}$ generally is not constant, and may be defined as [23]:

$$
b_{k}=\frac{4 c \lambda P_{m}}{r}
$$

where $\lambda$ is the mean free path of gas molecules (MFPG) in $\mathrm{m}, c$ is the proportionally factor and $r$ is the pore radius in $\mathrm{m}$. Value of $b_{k}$ is significant parameter, it influence the difference of $K_{g}$ and $K_{o}$ and may be changed with Knudsen number. Klinkenberg effect is also significant in fine grained, low porosity and extremely low permeability tight gas reservoirs such as shales [24]. Various Klinkenberg coefficient correlations are described by many researchers and are available in the literature [25]. Equation 3 is describing the Knudsen number ( $\mathrm{Kn}$ ) and has widely utilized to define the flow regimes as shown in Table 2 especially for shale porous media that contents small pore scales [5].

$$
K_{n}=\frac{\lambda}{r}
$$

Mean free path of gas molecules is mostly changes in respect to gas pressure, temperature and gas type and it may define as [26]:

$$
\lambda=\frac{K_{b} T}{\sqrt{2} \pi \delta_{m}^{2} p}
$$

where $K b$ is the Boltzmann constant $(1.38 \mathrm{E}-23 \mathrm{~J} / \mathrm{K}), \delta m$ is the gas molecule collision diameter in meter, $T$ is the temperature in Kelvin, and $p$ is the gas pressure in Pascal. Table 3 describing the gas molecule collision diameter of different gases [27] and it may be calculated from gas viscosity
Table 3: Collision diameter of gas molecules of different gases.

\begin{tabular}{cc}
\hline Gas type & Collision diameter $(\sigma \mathrm{m}), \mathrm{m}$ \\
\hline Helium & $0.26 \times 10^{-9}$ \\
Methane & $0.38 \times 10^{-9}$ \\
Carbon Dioxide & $0.33 \times 10^{-9}$ \\
Nitrogen & $0.36 \times 10^{-9}$ \\
\hline
\end{tabular}

( $\mu$ ) using the following equation [28].

$$
\delta_{m}^{2}=\frac{2 \sqrt{m K_{b} T}}{3 \pi^{\frac{3}{2}} \mu}
$$

where $m$ is the molecule mass and other requisite fluid parameters can be obtained by using NIST Standard Reference data base 23 .

\subsection{Gas apparent permeability model}

Gas apparent permeability is very important parameter for understanding of shale mechanisms and it mostly depends on Knudsen number and intrinsic or absolute permeability [29]. In shale gas reservoir, the apparent permeability variation may causes of different flow regimes and availability of small pore scales especially in shale matrix [30]. Different flow regimes such are identified based on this relationship. Knudsen number is also affected by gas adsorption-induced pore radius; therefore it would be better to correct the Knudsen number before measurement of shale gas apparent permeability. B-K is the most common apparent permeability model presented by Beskok [10], based on a unified Hagen-Poiseuille-type equation for shale. It can be expressed as:

$$
K_{\text {aap }}=K_{\infty} f\left(K_{n}\right)
$$


where $K_{\text {aap }}$ is the apparent permeability and $f\left(K_{n}\right)$ is the term that shows slippage incremental and it may be defined as:

$$
f\left(K_{n}\right)=\left(1+\zeta K_{n}\right)\left(1+\frac{4 K_{n}}{1-b K_{n}}\right)
$$

where $\zeta$ is the dimensionless rarefaction coefficient and $b$ is the slip coefficient. It has found from literature that the $b$ is empirical parameter, does not depend on gas type and it value is -1 suggested by Beskok and Karniadakis. Further, he also suggested dimensionless rarefaction coefficient values and its varies as $0<\zeta<\zeta_{0}$ for $0<\mathrm{K}_{n}<\infty$ where $\zeta_{o}$ is an asymptotic limit value. Civan et al. [6] is presented the following correlation for dimensionless rarefaction coefficient determination.

$$
\zeta=\frac{\zeta_{o}}{1+\frac{A}{K_{n}{ }^{B}}}
$$

where $\mathrm{A}=0.17, \mathrm{~B}=0.4348$ and $\zeta_{o}=1.358$.

Alteration in shale matrix permeability may be causes of two difference effect i.e. effective stress and flow regimes that may occur when pressure declines as gas production starts. Alter the intrinsic or absolute gas permeability and pores network structure may cause of effective stress effects while alter the gas apparent permeability because of slippage factor may cause of flow regimes effects [31, 32]. The effective stress equation can be defined as [33]:

$$
\sigma_{e f f}=P_{c}-\alpha P_{p}
$$

where, $\sigma_{\text {eff }}$ is the effective stress; $P_{c}$ is the confining pressure, $P_{p}$ is the pore pressure and $\alpha$ is the effective stress coefficient. The Stress dependence of gas permeability may be defined as:

$$
K_{\infty}=K_{\infty, o} \exp \left(-\alpha_{k} \sigma_{\text {eff }}\right)
$$

where $K_{\infty}$ is the Klinkenberg-corrected gas permeability coefficient at zero effective stress $(\sigma=0)$ and $\alpha_{k}$ an adjustable parameter (related to pore compressibility) indicating stress sensitivity. Combining equation 9 and 10 with equation 1 and new proposed equation, the new gas apparent permeability becomes as:

$$
\begin{gathered}
K_{g}=K_{\infty, o} \exp \left[-\sigma_{k}\left(P_{c}-\alpha P_{p}\right)\right]\left(1+\frac{b}{P}\right) \\
K_{g}=K_{\infty, o} \exp \left[-\sigma_{k}\left(P_{c}-\alpha P_{p}\right)\right]\left(1+\frac{b \_c o r}{P}\right)
\end{gathered}
$$

\subsection{Gas adsorption models}

In shale gas reservoirs, a network of pore scales and transport processes are providing a path to gas flow [34] and usually small size pores make the SSA large; therefore, transport processes are very important that depending on SSA where adsorption, desorption and diffusion occur. Various shale gas adsorption models have been developed and used for the measurement of gas sorption capacity such as Langmuir, Brunauer-Emmett-Teller (BET), Dubinin-Astakhov (D-A), Dubinin and Radushkevich (DR) and Freundlich model [35, 36]. In this study D-A model was used because it provides better outcomes as compare to other adsorption models. Dubinin and his coworkers developed following two equations for measurement of gas sorption capacity:

$$
\begin{array}{ll}
\text { D-A model : } & V=V_{O} \exp \left(-D\left[\ln \left(\frac{\rho_{a}}{\rho_{g}}\right)\right]^{n}\right) \\
\text { D-R model : } & \quad V=V_{O} \exp \left(-D\left[\ln \left(\frac{P_{O}}{P}\right)\right]^{2}\right)
\end{array}
$$

where $V$ is absolute adsorption, $V_{0}$ is maximum gas sorption capacity, $n$ and $D$ is structural heterogeneity (varies between 1 and 4) and pore structure parameter, $P_{0}$ and $P$ is the saturation and equilibrium vapor pressure respectively. Equation 13 is known as D-A equation whereas equation 14 is known as $\mathrm{D}-\mathrm{R}$ equation. The Langmuir model is the most common model that is used to measure gas adsorption. It can be used to fit excess adsorption data expressed by equation 15 .

$$
n_{e x}=\frac{n_{L} P}{P_{L}+P}\left(1-\frac{\rho_{g}}{\rho_{a}}\right)
$$

Based on Langmuir and D-A model, $\mathrm{V}$ can be substituted by mole number $\mathrm{n}$, and then equation 13 can be rewritten as [37]:

$$
n_{e x}=n_{O} \exp \left(-D\left[\ln \left(\frac{\rho_{a}}{\rho_{g}}\right)\right]^{2}\right)\left(1-\frac{\rho_{g}}{\rho_{a}}\right)
$$

where $n_{e x}$ is the excess adsorption capacity in $\mathrm{mmol} / \mathrm{g}, n_{L}$ and $n_{0}$ is the maximum absolute gas adsorption capacity of monolayer adsorption and micropore- filling capacity in $\mathrm{mmol} / \mathrm{g}, P$ and $P_{L}$ is the equilibrium pressure and Langmuir pressure in MPa and $\rho_{g}$ and $\rho_{a}$ is the density of free and adsorbed gas in $\mathrm{g} / \mathrm{cm}^{3}$. Adsorbed layer thickness is mostly affects the pore radius. Pore radius can be expressed as:

$$
r=r_{o}-\Delta r
$$

where $r, r_{o}$ and $\Delta r$ is the average pore radius, initial pore radius and adsorbed layer thickness in $\mathrm{m}$. Based on equation 16, the adsorbed layer thickness may be expressed 
as [36]:

$$
\Delta r=\frac{W_{a d s}}{\rho_{a} S}=\frac{W_{O}}{\rho_{a} S} \exp \left(-D\left[\ln \left(\frac{\rho_{a}}{\rho_{g}}\right)\right]^{2}\right)
$$

where $W o$ is the maximum gas sorption capacity in $\mathrm{mol} / \mathrm{g}$ and $S$ is the specific surface area, $\mathrm{m}^{2} / \mathrm{g}$ and $\rho_{a}$ is the adsorbed gas density in $\mathrm{mol} / \mathrm{m}^{3}$. It may be taken from the adsorption isotherms. Hence equation 17 can be re-written as:

$$
\begin{aligned}
r_{-} \text {cor } & =r_{o}-\frac{W_{a d s}}{\rho_{a} S} \\
& =r_{o}-\frac{W_{O}}{\rho_{a} S} \exp \left(-D\left[\ln \left(\frac{\rho_{a}}{\rho_{g}}\right)\right]^{2}\right)
\end{aligned}
$$

where r_cor represents gas adsorption-induced pore radius. Further, based on this equation, the equation 1 can be modifying as:

$$
\begin{gathered}
K_{g}=K_{o}\left(1+\frac{b_{k}}{P_{m}}-\frac{b_{k_{-} c o r}}{P_{m}{ }^{2}}\right) \\
b_{k_{-} c o r}=\frac{4 c \lambda P_{m}}{r_{-} c o r}
\end{gathered}
$$

where $b_{k-}$ cor is the klinkenberg coefficient gas adsorptioninduced pore radius.

\section{Results and discussion}

\subsection{Impact of gas pressure and temperature on mean free path of gas molecules}

The temperature impact on mean free path of gas molecule in shale is very little as compare to gas pressure. But on other end, gas pressure has great influence on the MFPG.

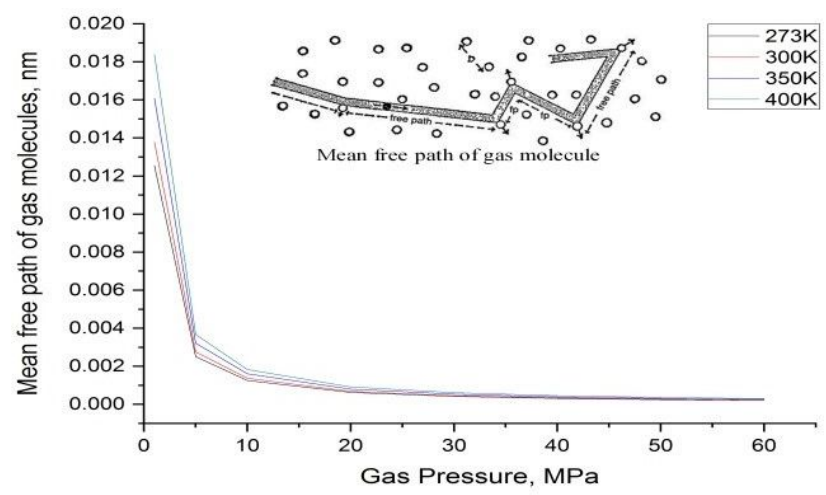

Figure 2: MFPG of Helium gas molecules under different temperature and pressure.
For helium gas when the pressure is less than 30MPa, MFPG increases sharply as pressure decreases and when the pressure is greater than $30 \mathrm{MPa}$, MFPG is less than 0.002 , and decreases slightly with the increase of pressure that can be seen in Figure 2. Gas molecule collision diameter of various gases has also great influence on the MFPG for shale sample as observed in Figure 3.

\subsection{Impact of gas adsorption induced pore radius on shale gas permeability}

It has been observed that equation 1 does not show the impact of gas adsorption-induced pore radius, therefore, addition term is required to modify such equation. Hence, based on equation 16 and 17 the new equation has been developed (i.e. equation 20). This equation contains the additional term which shows the pore thickness impacts and has providing good gas permeability results as compare equation 2 (Table 4). Further, Helium gas is a nonadsorbed gas and cannot be suitable for gas adsorption measurements. So, it would be better to use adsorbed gas such as methane when combine the study of gas adsorption and gas permeability. The use of same adsorbed gas for both measurements may provide a better description for shale gas characterization and in such case the new proposed equation may be appropriated.

From the Table 4, it was also observed that value of $\mathrm{b}_{k}$ has affected due to gas adsorption-induced pore radius and gas permeability decreases as pore radius decreases. However, this value may be more affected as its changes with increase or decrease of gas adsorption and specific surface area of samples. Further, two views of $b_{k}$ were obtained when it was assumed as a constant and variable (Figure 4).

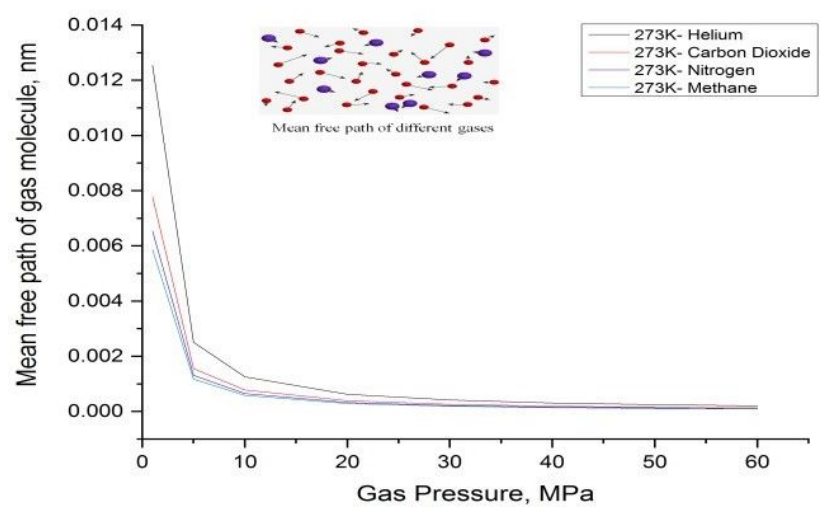

Figure 3: MFPG under same temperature and different pressure and gas types. 
Table 4: Corrected value of pore radius, Klinkenberg coefficient and gas permeability.

\begin{tabular}{|c|c|c|c|c|c|c|c|c|c|c|}
\hline $\begin{array}{c}\text { Sample } \\
\text { \# \& Gas } \\
\text { type }\end{array}$ & $\begin{array}{c}\text { Pmean, } \\
\text { Psia }\end{array}$ & $\begin{array}{c}\mathrm{r} \\
\mathrm{nm}\end{array}$ & $\begin{array}{c}\mathrm{r}_{\mathrm{n}} \text { cor, } \\
(\mathrm{Eq}-19)\end{array}$ & $\begin{array}{c}\text { bk } \\
(\text { Eq-1) }\end{array}$ & bk (Eq-2) & $\begin{array}{l}\text { bk_cor } \\
(E q-21)\end{array}$ & $\begin{array}{l}\mathrm{Kg}, \mathrm{nd} \\
\text { (Exp) }\end{array}$ & $\begin{array}{l}\mathrm{Kg}, \mathrm{nd} \\
(\mathrm{Eq}-1)\end{array}$ & $\begin{array}{l}\mathrm{Kg}, \mathrm{nd} \\
(\mathrm{Eq}-2)\end{array}$ & $\begin{array}{c}\text { Kg_cor, } \\
\text { nd } \\
(E q-20)\end{array}$ \\
\hline \multirow[t]{3}{*}{$2-\mathrm{He}$} & 114 & 50 & 49.888 & 202.3 & 204.375 & 204.83 & 195 & 195.024 & 196.304 & 195.196 \\
\hline & 449 & & 49.811 & & 204.378 & 205.154 & 102 & 101.960 & 102.285 & 102.214 \\
\hline & 964 & & 49.771 & & 204.375 & 205.316 & 85 & 85.041 & 85.192 & 85.177 \\
\hline \multirow[t]{6}{*}{$2-\mathrm{CH} 4$} & 114 & 30 & 29.888 & 133 & 159.462 & 160.06 & 41 & 41.449 & 45.889 & 45.654 \\
\hline & 214 & & 29.853 & & 159.462 & 160.247 & 32 & 31.020 & 33.385 & 33.318 \\
\hline & 464 & & 29.809 & & 159.462 & 160.484 & 24 & 24.614 & 25.705 & 25.691 \\
\hline & 715 & & 29.786 & & 159.685 & 160.833 & 24 & 22.689 & 23.403 & 23.397 \\
\hline & 964 & & 29.771 & & 159.462 & 160.689 & 21 & 21.770 & 22.295 & 22.292 \\
\hline & 1965 & & 29.742 & & 159.462 & 160.845 & 20 & 20.425 & 20.683 & 20.682 \\
\hline \multirow[t]{4}{*}{$5-\mathrm{He}$} & 115 & 31 & 30.874 & 331.4 & 329.637 & 330.98 & 315 & 318.808 & 317.549 & 315.496 \\
\hline & 463 & & 30.767 & & 329.635 & 332.162 & 162 & 140.916 & 140.603 & 140.481 \\
\hline & 965 & & 30.711 & & 237.409 & 239.643 & 103 & 110.336 & 110.186 & 110.145 \\
\hline & 1965 & & 30.668 & & 329.642 & 333.211 & 86 & 95.982 & 95.908 & 95.901 \\
\hline \multirow[t]{6}{*}{$5-\mathrm{CH} 4$} & 115 & 12 & 11.908 & 311.2 & 398.654 & 401.743 & 85 & 102.584 & 123.634 & 122.793 \\
\hline & 215 & & 11.868 & & 398.654 & 403.093 & 54 & 67.745 & 79.004 & 78.763 \\
\hline & 465 & & 11.809 & & 398.649 & 405.104 & 38 & 46.205 & 51.41 & 51.358 \\
\hline & 716 & & 11.773 & & 398.654 & 406.336 & 34 & 39.711 & 43.092 & 43.069 \\
\hline & 966 & & 11.749 & & 398.656 & 407.192 & 30 & 36.597 & 39.103 & 39.091 \\
\hline & 1969 & & 11.694 & & 398.654 & 409.058 & 26 & 32.054 & 33.284 & 33.28 \\
\hline
\end{tabular}

Table 5: TOC, SSA and fitted parameters based on Langmuir and DR model for eight shale samples [39].

\begin{tabular}{|c|c|c|c|c|c|c|c|c|}
\hline \multirow[t]{2}{*}{$\begin{array}{c}\text { Sample } \\
\quad \#\end{array}$} & \multirow[t]{2}{*}{$\begin{array}{l}\text { TOC } \\
(\%)\end{array}$} & \multirow[t]{2}{*}{$\begin{array}{l}\mathrm{SSA}^{*} \\
\left(\mathrm{~m}^{2} / \mathrm{g}\right)\end{array}$} & \multicolumn{3}{|c|}{$\begin{array}{l}\text { Langmuir-based excess adsorption } \\
\qquad(\text { Eq-15) }\end{array}$} & \multicolumn{3}{|c|}{$\begin{array}{l}\text { DR-based excess adsorption } \\
\qquad(\text { Eq-16) }\end{array}$} \\
\hline & & & $\begin{array}{c}\mathrm{nL}, \\
\mathrm{mmol} / \mathrm{g}\end{array}$ & $\mathrm{PL}, \mathrm{MPa}$ & $\rho \mathrm{a}, \mathrm{g} / \mathrm{cm}^{3}$ & $\begin{array}{c}\mathrm{no}, \\
\mathrm{mmol} / \mathrm{g}\end{array}$ & $\rho \mathrm{a}, \mathrm{g} / \mathrm{cm}^{3}$ & $\mathrm{D}$ \\
\hline$X 2-1$ & 4.1 & 23.43 & 0.132 & 1.50 & 0.391 & 0.139 & 0.343 & 0.059 \\
\hline$X 2-2$ & 5.3 & 19.65 & 0.151 & 1.76 & 0.357 & 0.156 & 0.321 & 0.062 \\
\hline$x 2-3$ & 5.8 & 22.60 & 0.159 & 1.33 & 0.526 & 0.176 & 0.414 & 0.053 \\
\hline$X 2-4$ & 2.8 & 16.06 & 0.079 & 2.37 & 0.213 & 0.073 & 0.212 & 0.085 \\
\hline X3-1 & 3.1 & 9.83 & 0.078 & 1.90 & 0.262 & 0.076 & 0.257 & 0.069 \\
\hline X3-2 & 4.3 & 11.81 & 0.093 & 1.64 & 0.302 & 0.093 & 0.291 & 0.061 \\
\hline X3-3 & 3.7 & 12.17 & 0.089 & 1.77 & 0.282 & 0.088 & 0.274 & 0.065 \\
\hline X3-4 & 3.5 & 11.90 & 0.084 & 1.88 & 0.298 & 0.081 & 0.292 & 0.063 \\
\hline
\end{tabular}

${ }^{\star}$ Specific surface area (SSA) is measured by using BET equation [21].

\subsection{Impact of gas adsorption capacity on pore radius}

Gas adsorption capacity is a function of TOC as well as SSA [38]. TOC is interrelated with gas adsorption capacity and SSA. The shale pore radius is affected due to gas adsorption capacity as observed in literature. For example, at the same initial pore size i.e. $2 \mathrm{~nm}$, average pore radius effects are varied at different shale samples and this is may be existence of organic matter and mineral components. Table 5 describes the gas adsorption data of shale samples and same data were used to investigate the impact of gas adsorption on pore radius. The result of gas adsorptioninduced pore radius at different pressure can be seen in Figure 5. It was observed from figure that the pore radius is deceases as pressure increases and the behavior of gas adsorption-induced pore radius reduction was found different as each sample has different characteristics. Hence, 
it is cleared from this outcome that gas adsorption capacity is a key factor that affects pore radius of shale.

Further, it was also observed in Figure 5 that pore radius is more affected at low pressure (1-10MPa) as compare to high Pressure (above 10MPa) at different shale samples. The D-R model provides the better results as compare with Langmuir adsorption model (Figure 6) because D-R model is built based on the micropore-filling mechanism whereas Langmuir model assumes monomolecular layer adsorption on pore surfaces [40].

The relation in between gas adsorption capacity with TOC and SSA can be seen in Figure 7. It was observed from this figure that both TOC and SSA is varies with kerogen quality. For example sample 1-3 and 8 content very good kerogen quality ( 4 to $12 \%$ ) but high TOC and low SSA has found in sample 1-3 whereas high TOC and high SSA has found in sample 8. Similarly, sample 4 and 5-7 content low kerogen quality ( $<4 \%$ ) but low TOC and high SSA has found in sample 4 whereas low TOC and low SSA has found in sample 5-7. Hence, it is observed from results that TOC and SSA are the controlling factors of methane gas adsorption capacity and provides useful information for shale gas measurement and development. From the literature, it was also found that the methane gas adsorption capacities of the organic matter such as kerogen and mineral components are important for evaluating the methane gas adsorption capacity for shales [41]. Further, different shale samples have contains different SSA and gas adsorption capacity whereas parameters may vary due to presence of kerogen type and mineral components in shale sample. For example, SSA of Kerogen-isolated has found in Longmaxi Formation shales is $193.1 \mathrm{~m}^{2} / \mathrm{g}$ [42] whereas 161.23 $\mathrm{m}^{2} / \mathrm{g}$ has found in Niutitang Formation shales [43]. Similarly, SSA of mineral components has found different in different shale samples $[44,45]$.

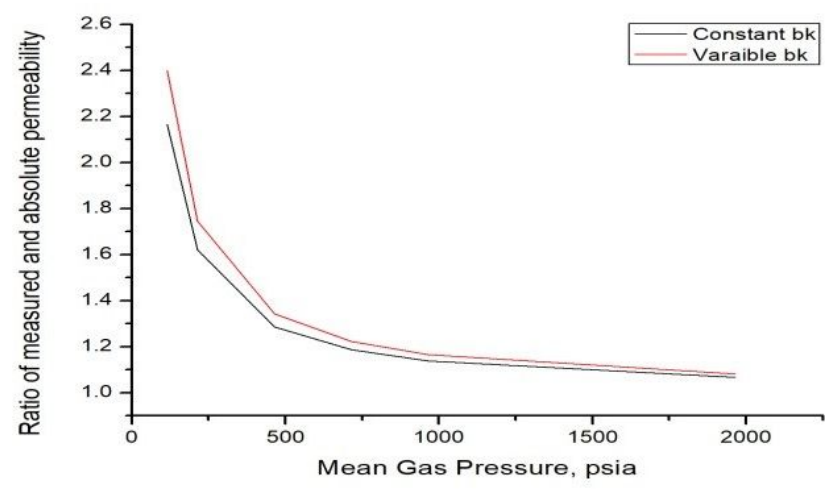

Figure 4: Views of constant and variable Klinkenberg coefficient at methane gas for sample 2 .

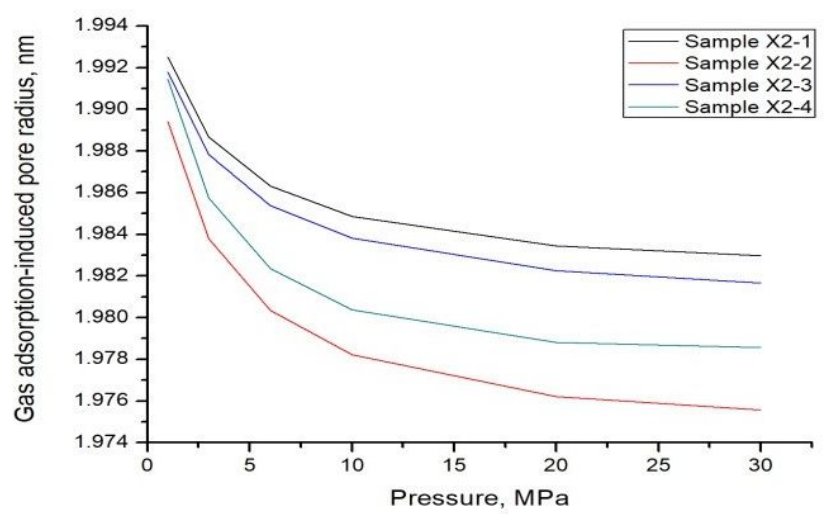

Figure 5: Impacts of gas adsorption- induced pore radius on gas adsorption capacity at various pressures.

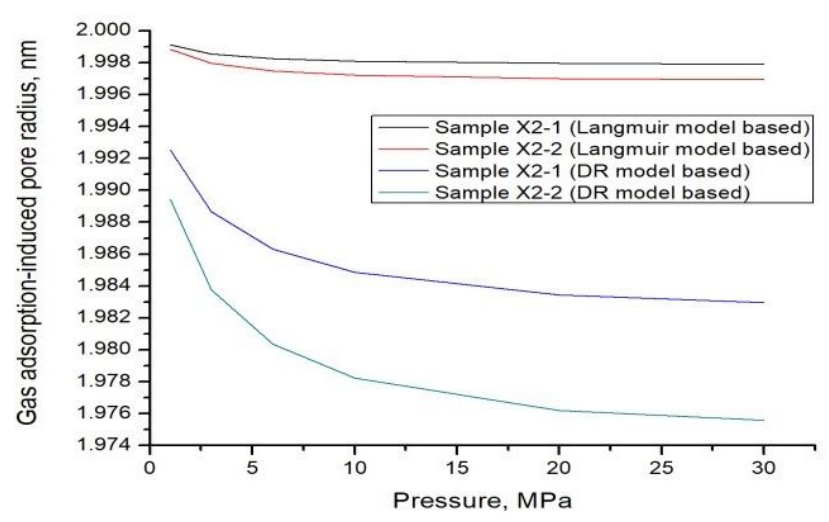

Figure 6: Comparison of Langmuir and DR model at various pressures and different Shale samples.

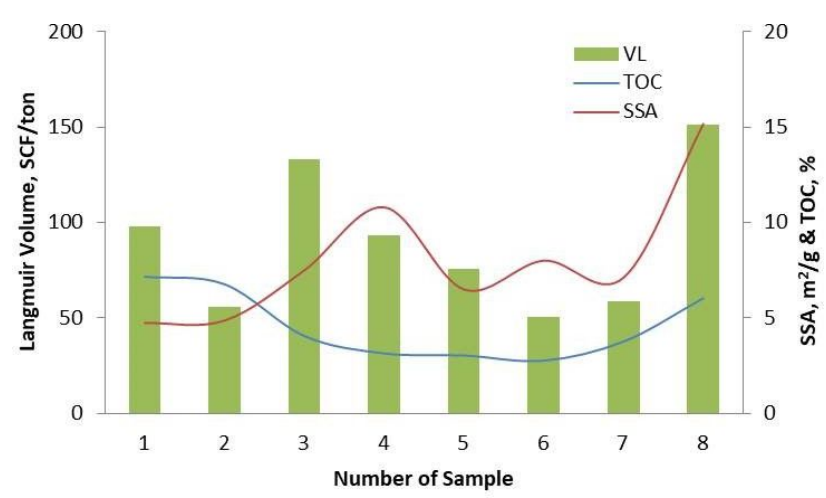

Figure 7: Relation between $\mathrm{V}_{L}$, TOC and SSA at different shale samples.

\subsection{Impact of effective stress changes on pore radius}

As discussed above that the gas adsorption have an effect on the pore radius but on other end the effective stress is also effect on pore radius as observed in literature [24, 29]. The variation in effective stress is influenced on pore ra- 

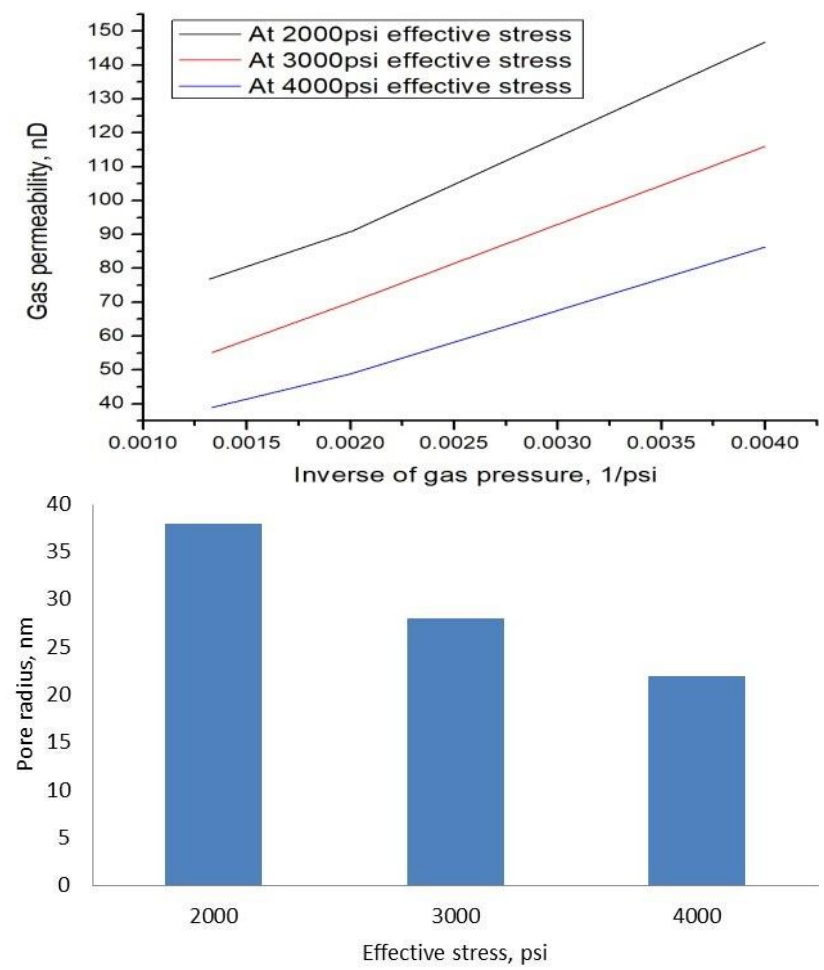

Figure 8: Effect of effective stress on pore radius and gas permeability.

dius and result gas permeability change. Figure 8 describe that the effect of effective stress changes on gas permeability and pore radius [29]. It has been observed from this figure that pore radius is deceases as effective stress increases and due to this effect the gas permeability is decreases and also relation in between the effective stress and pore size is linearly found.

\subsection{Impact of pore size and flow regimes on gas apparent permeability}

The relation between gas permeability and apparent permeability at different gases such as helium and methane is shown in Figure 9. Further, it was noted that gas apparent permeability is always higher than gas permeability and its value may vary with intrinsic permeability and flow regimes as well.

\subsection{Impact of slip flow and effective stress on gas apparent permeability}

As discussed above that when effective stress increases, the pore radius and gas permeability is decreases. But on other hand, due to increase of effective stress, the slip-

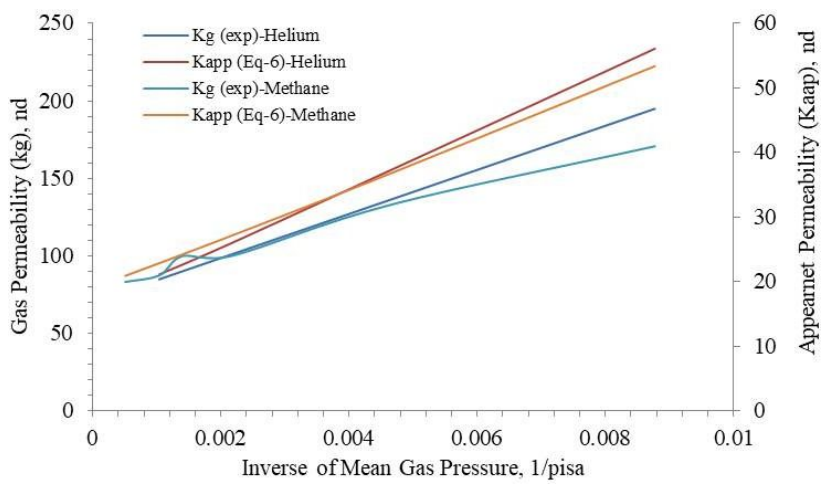

Figure 9: Gas permeability and apparent permeability at different gases for sample 2 .

flow parameters also change and result slip effect that enhances the gas apparent permeability. Figure 10 shows the same effect as described above and further changes in Klinkenberg coefficient due to gas adsorption-induced pore radius may cause of increases Klinkenberg gas permeability. Hence, combine impact of slip flow and effective stress with Klinkenberg coefficient gas adsorptioninduced pore radius is very important and provides understanding in evolution of gas apparent permeability during shale gas production.

Effective stress coefficient is equal to one according to the statement of Terzaghi's principle [46] but in shale gas, the gas apparent permeability is more sensitive to confining pressure variation than pore pressure. Hence, this principle is not likely to be valid in evaluation of shale gas permeability. Figure 11 shows the effective stress coefficient increases as gas apparent permeability decreases when slip is considered. Further, it was observed that no effective stress coefficient impact was found at gas apparent permeability when slip flow is not considered. Hence, it has been cleared from this outcome that the impact of effective stress coefficient is larger at gas apparent permeability when slip flow is considered and smaller when slip flow is not considered.

\section{Conclusion}

Based on above study, it is concluded that:

1. Klinkenberg cofficient value is affected due to gas adsorption-induced pore radius impacts and resulted in a change in gas permeability. However, this value may be more affected as it changes with increase or decrease of gas adsorption capacity and specific surface area of shale samples. 

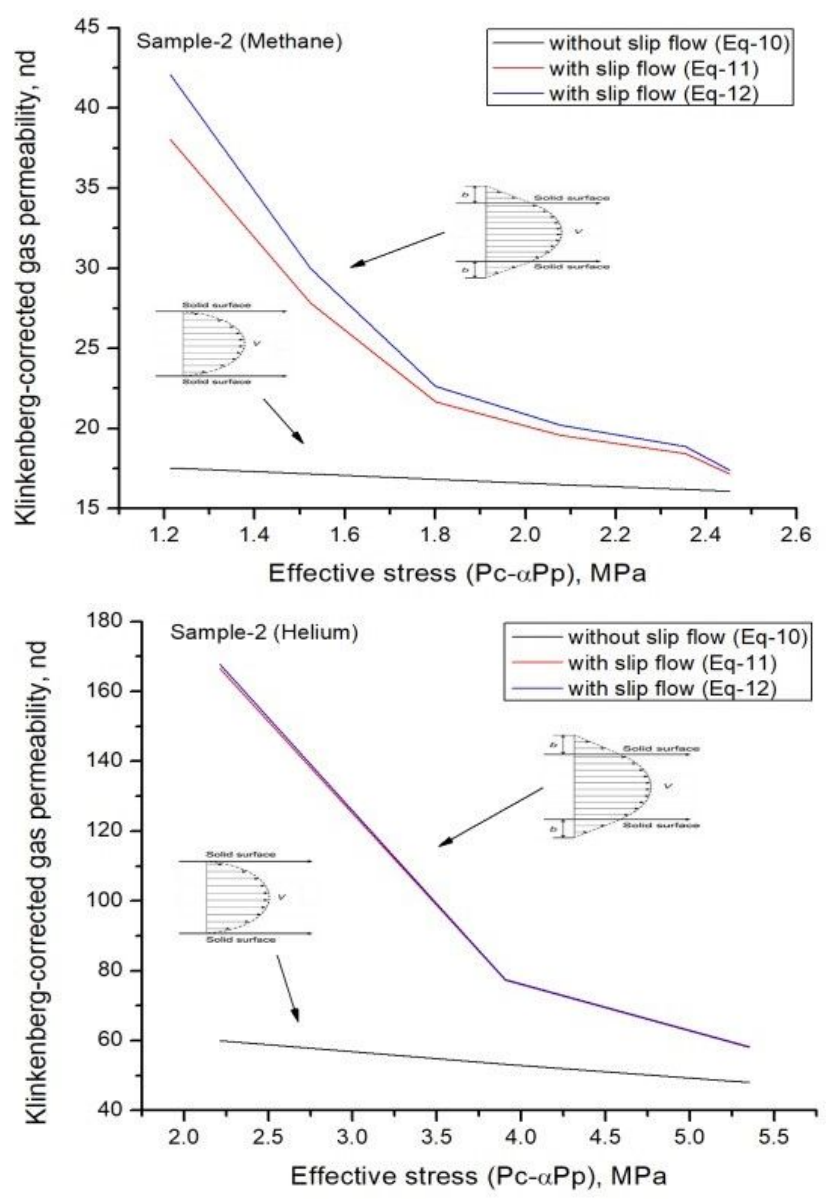

Figure 10: Impact of Slip flow and effective stress on Permeability due to Klinkenberg coefficient gas adsorption-induced pore radius at different gases.

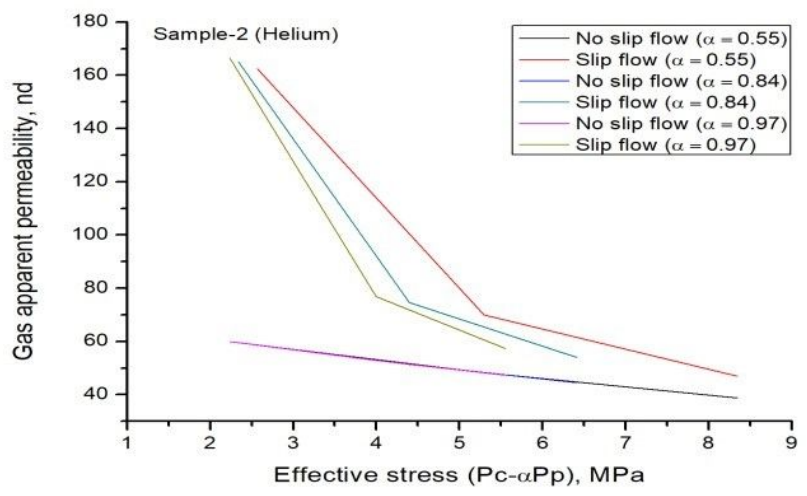

Figure 11: Impact of effective stress coefficient on gas apparent permeability at with/without slip flow.

2. Gas permeability measured from new proposed model is provide good results in slip flow region as compare to existing equation.

3. Gas adsorption parameters such as sorption capacity, total organic content and specific surface area are the major factors that affect the pore radius of shale. Different shale samples contain different specific surface area and gas adsorption capacity; therefore, values of these parameters may vary due to presence of kerogen type and mineral components.

4. Knudsen number is affecting due to gas adsorptioninduced pore radius; therefore it is better to correct the Knudsen number before measurement of shale gas apparent permeability.

5. Pore radius is affected due to change of effective stress and result change in gas permeability.

6. Slip effect enhances the gas apparent permeability and also change with effective stress; therefore, combine impact of slip flow and effective stress is very important and provides understanding in evolution of gas apparent permeability during shale gas production.

7. Both organic and inorganic materials are present and play a key role for shale gas characterization; therefore, impact of organic and inorganic material on shale gas properties and gas adsorption capacity will be investigated in future work.

Acknowledgement: This work was supported by the National Natural Science Foundation of China (NO.51774308) and the National Science and Technology Major Project of China (2016ZX05014-003-002).

\section{References}

[1] Moghadam, A.A., and Chalaturnyk, R., Analytical and Experimental Investigations of Gas-Flow Regimes in Shales considering the Influence of Mean Effective Stress, SPE Journal, 2016, Doi:10.2118/178429-PA

[2] Cao, J., Liang, Y., Masuda, Y., Koga, H., Tanaka, H., Tamura, K., Matsuoka, T., Molecular Simulation of Methane Adsorption Behavior in Kerogen Nanopores for Shale Gas Resource Assessment, International Petroleum Technology Conference, 2019, Doi:10.2523/IPTC-19216-MS

[3] Guang-pu, Z., Jun, Y., Hai, S., Min, Z., Mei-jie, X., Zhi-xue, S., Tao, L., The numerical simulation of thermal recovery based on hydraulic fracture heating technology in shale gas reservoir, Journal of Natural Gas Science and Engineering, 2016, 305-316, Doi:10.1016/j.jngse.2015.11.051

[4] Alharthy, N. S., Teklu, T. W., Abd El-Gawad, S., Kazemi, H., \& Graves, R., Flow Dynamics and Pore Scale Physics in Unconventional Shale Reservoirs. Unconventional Resources Technology Conference, 2017, Doi:10.15530/URTEC-2017-2698056

[5] Javadpour, F., Nanopores and apparent permeability of gas flow in mudrocks; shales and siltstone, JCPT, 2009, 48 (8), 16-21, Doi:10.2118/09-08-16-DA

[6] Civan, F., Rai, C.S., Sondergeld, C.H., Shale-gas permeability and diffusivity inferred by improved formulation of relevant retention 
and transport mechanisms. Transport in Porous Media, 2011, 925-944, Doi:10.1007/s11242-010-9665-x

[7] Sakhaee-pour, A., \& Bryant, S. L., Gas Permeability of Shale, presented at the Annual Technical conference and Exibition for the Society of Petroleum Engineer, Colorado, USA, $30^{\text {th }}$ oct- $2^{\text {nd }}$ Nov, 201, Doi:10.2118/146944-PA

[8] Shi, J., Zhang, L., L i, Y., et al., Diffusion and flow mechanisms of shale gas through matrix pores and gas production forecasting, presented at the SPE Unconventional Resources Conference-Canada Heldin Calgary, Alberta, Canada, 2013, Doi:10.2118/167226-MS

[9] Zhang, X., Xiao, L., Guo, L., Xie, Q., Investigation of shale gas microflow with the Lattice Boltzmann method, Petroleum Science, 2015, 12 96-103, Doi:10.1007/s12182-014-0004-7

[10] Beskok, A., Karniadakis, G.E., Report: a model for flows in channels, pipes, and ducts at micro and nano scales, Microscale Thermophys. Eng, 1999, 3(1), 43-77, Doi:10.1080/108939599199864

[11] Zhang, L.J., Li, D.L., Lu, D.T., Zhang, T., A new formulation of apparent permeability for gas transport in shale, J. Nat. Gas Sci. Eng, 2015, 23, 221-226, Doi:10.1016/j.jngse.2015.01.042

[12] Freeman, C. M., Moridis, G. J., Blasingame, T. A., A numerical study of microscale flow behavior in tight gas and shale gas reservoir systems, Transp. Porous Med, 2011, 1, 253-268, Doi:10.1007/s11242-011

[13] Darabi, H., Ettehad, A., Javadpour, F., Sepehrnoori, K., Gas flow in ultra-tight shale strata. J. Fluid Mech, 2012, 641-658, Doi:10.1017/jfm.2012.424

[14] Naraghi, M.E., Javadpour, F., A stochastic permeability model for the shale-gas systems, Int. J. Coal Geol, 2015, 140, 111-124, Doi:10.1016/j.coal.2015.02.004

[15] Weichao, Yan., Jianmeng, Sun., Jinyan, Zhang., Naser, Golsanami., Shuyan, Hao., A novel method for estimation of remaining oil saturationsin water-flooded layers, Interpretation, 2017, Vol. 5, No. 1, SB9-SB23, Doi:10.1190/INT-2016-0074.1

[16] Yan,W., Sun,J., Sun,Y., Golsanami,N., Arobust NMR method to measure porosity of low porosity rocks, Microporous Mesoporous Mater, 2018, Doi:10.1016/j.micromeso.2018.02.022

[17] Golsanami, N., Sun, J., Liu, Y., Yan, W., Lianjun, C., Jiang, L., Dong, H., Zong, C., Wang, H., Distinguishing fractures from matrix pores based on the practical application of rock physics inversion and NMR data: A case study from an unconventional coal reservoir in China, J. Nat. Gas Sci. Eng, 2019, 65, 145-167, Doi:10.1016/j.jngse.2019.03.006

[18] Jose, M. C., Davide, G., Ting, Y., and Jing, B., Effect of Clay and Mineralogy on Permeability, Pure Applied Geophysics, 2019, Vol. 176, 2581-2594, Doi:10.1007/s00024-019-02117-3

[19] Al, Ismail. M. I., Zoback, M. D., Effects of rock mineralogy and pore structure on stress- dependent permeability of shale samples, Phil. Trans. R. Soc. A, 2016, 374, 04-28, Doi:10.1098/rsta.2015.0428

[20] Sinha, S., Braun, E.M., Passey, Q.R., Onardi, S.A., Boros, J.A., Wood, A.C., Zirkle, T., Kudva, R.A., Steady-State Permeability Measurements on Intact Shale Samples at Reservoir Conditions - Effect of Stress, Temperature, Pressure, and Type of Gas, presented at Middle East Oil and Gas Show and Conference for the Society of Petroleum Engineers, Manama, Bahrain. March 10-13, 2013, Doi:10.2118/164263-MS

[21] Klinkenberg, L.J., The permeability of porous media to liquid and gases, paper presented at the API 11th mid-year meeting for the API Drilling and Production Practice Tulsa, Oklahoma, 1941
[22] Bao, J., Dandan, L., Jyun-Syung, T., Gas Permeability Evolution During Production in the Marcellus and Eagle Ford Shales: Coupling Diffusion/Slip-flow, Geomechanics, and Adsorption/Desorption, presented at unconventional Resources Technology Conference for the Society of Petroleum Engineers, Austin, Texas, USA. July 24-26, 2017, Doi:10.15530/URTEC-20172695702.

[23] Aljamaan H., Petrophysical Investigation on Gas Transport Properties of the Barnett Shale, presented at Annual Technical Conference and Exhibition for the Society of Petroleum Engineers, New Orleans, Louisiana, USA, 30 September - 2 October 2013, Doi:10.2118/167624-STU

[24] Juntai, Shi., Lei, Zhang., Yuansheng, Li., Wei, Yu., Xiangnan, He., Ning, Liu., Xiangfang., Li, Diffusion and flow mechanisms of shale gas through matrix pores and gas production forecasting, presented at the Unconventional Resources Conference for the Society of Petroleum Engineers Alberta, Canada, Nov 5-7, 2013, Doi:10.2118/167226-MS

[25] Gongda, Wang., Ting, Ren., Kai, Wang., Aitao, Zhou., Improved apparent permeability models of gas flow in coal with Klinkenberg effect, Fuel, 2014, 128, 53-61, Doi:10.1016/j.fuel.2014.02.066

[26] Yan, Peng., Jishan, Liu., Zhejun, Pan., Hongyan, Qu., Luke, Connell., Evolution of shale apparent permeability under variable boundary conditions, Fuel, 2018, 215, 46-56, Doi:10.1016/j.fuel.2017.11.024

[27] Rasoul, N. M., Mahmoud, J., Fluid transport in shale gas reservoirs: Simultaneous effects of stress and slippage on matrix permeability, International Journal of Coal Geology, 2016, 163, 87-99, Doi:10.1016/j.coal.2016.06.018

[28] Bao, J., Dandan, L., Jyun-Syung, T., Gas Permeability Evolution During Production in the Marcellus and Eagle Ford Shales: Coupling Diffusion/Slip-flow, Geomechanics, and Adsorption/Desorption, presented at unconventional Resources Technology Conference for the Society of Petroleum Engineers, Austin, Texas, USA. July 24-26, 2017, Doi:10.15530/URTEC-20172695702

[29] Zhang, L., Li, D., Lu, D., Zhang, T., A new formulation of apparent permeability for gas transport in shale, J. Nat. Gas Sci. Eng, 2015, 221-226, Doi:10.1016/j.jngse.2015.01.042

[30] Ghanizadeh, A., Clarkson, C., Aquino, S., Ardakani, O., Sanei, H., Petrophysical and geomechanical characteristics of Canadian tight oil and liquid-rich gas reservoirs: I pore network and permeability characterization, Fuel, 2015, 664-681, Doi:10.1016/j.fuel.2015.03.020

[31] Wenhui, S., Jun, Y., Yang, L., Hai, S., Lei, Z., Yongfei, Y., Jianlin, Z., Hongguang, S., Apparent gas permeability in an organic-rich shale reservoir, Fuel, 2016, 181, 973-984, Doi:10.1016/j.fuel.2016.05.011

[32] Zhongwei, Chen., Zhejun, Pan., Jishan, Liu., Luke, D., Connell, D.E., Effect of the effective stress coefficient and sorptioninduced strain on the evolution of coal permeability: Experimental observations. International Journal of Greenhouse Gas Control, 2011, 1284-1293, Doi:10.1016/j.ijggc.2011.07.005

[33] Ambrose, R.J., Hartman, R.C.H., Campos, M.D., Akkutlu, I.Y., Sondergeld, $C$., New pore-scale considerations for shale gas in place calculations, presented at Unconventional Gas Conference for the Society of Petroleum Engineers, Pennsylvania, USA, Feb 2325, 2010, Doi:10.2118/131772-MS 
[34] Yang, Wang., Yanming, Zhu., Shimin, Liu., Rui, Zhang., Methane adsorption measurements and modeling for organic-rich marine shale samples, Fuel, 2016, 172, 301309, Doi:10.1016/j.fuel.2015.12.074

[35] Tianyi, Zhao., Xiangfang, Li., Huawei, Zhao., and Xiangji, Dou., Micro-storage State and Adsorption behavior of Shale Gas, presented at Nigeria Annual International Conference and Exhibition for the Society of Petroleum Engineers, Lagos, Nigeria, 4-6 August, 2015, Doi:10.2118/178386-MS

[36] Tian, H., Li, T., Zhang, T., Xiao, X., Characterization of methane adsorption on over-mature Lower Silurian-Upper Ordovician shales in Sichuan Basin, Southwest China: experimental results and geological implications, Int J Coal Geol, 2016, 156, 36-49, Doi:10.1016/j.coal.2016.01.013

[37] Juhyun, Kim., Donghyun, Kim., Wonsuk, Leeb., Youngsoo, Lee., Hyunjung, Kim., Impact of total organic carbon and specific surface area on the adsorption capacity in Horn River shale, Journal of Petroleum Science and Engineering, 2017, 331-339, Doi.org/10.1016/j.petrol.2016.10.053

[38] Shangwen, Zhou., Huaqing, Xue., Yang, Ning., Wei, Guo., Qin, Zhang., Experimental study of supercritical methane adsorption in Longmaxi shale: Insights into the density of adsorbed methane, Fuel, 2017, 140-148, Doi:10.1016/j.fuel.2017.09.065

[39] Zhang, T., Ellis, G.S., Ruppel, S.C., Milliken, K., Yang, R. E., Effect of organic-matter type and thermal maturity on methane adsorption in shale-gas systems, Org Geochem, 2012, 120-31, Doi:10.1016/j.orggeochem.2012.03.012

[40] Jian, Xiong., Xiangjun, Liu., Lixi, Liang., Qun, Zeng, Adsorption of methane in organic-rich shale nanopores: An experimental and molecular simulation study, Fuel, 2017, 299-315, Doi:10.1016/j.fuel.2017.03.083
[41] Xue, H., Wang, H., Liu, H, Yan G., Guo, W., Li, X., Adsorption capability and aperture distribution characteristics of shales: taking the Longmaxi formation shale of Sichuan Basin as an example, Acta Petrolei Sinica, 2013, 34(5), 826-32, Doi:10.7623/syxb201305003

[42] Cao, T., Song, Z., Wang, S., Xia, J., A comparative study of the specific area and pore structure of different shales and their kerogens, Science China Press, 2015, 45(2), 139-51, Doi:10.1007/s11430-014-5021-2

[43] Ji, L., Zhang, T., Milliken, K.L., Qu, J., Zhang, X., Experimental investigation of main controls to methane adsorption in clay-rich rocks, Applied Geochemistry, 2012, 27(12), 2533-2545, Doi:10.1016/j.apgeochem.2012.08.027

[44] Liu, D., Yuan, P., Liu, H., Li, T., Tan, D., Yuan, W., High-pressure adsorption of methane on montmorillonite, kaolinite and illite, Appl Clay Sci, 2013, 85, 25-30, Doi:10.1016/j.clay.2013.09.009

[45] E, Tang. S., Zhang, C., Guo, Q., Sun, C., Methane sorption capacity of organics and clays in high-over matured shale-gas systems, Energy Explor Exploit, 2014, 32(6), 927-42, Doi:10.1260/01445987.32.6.927

[46] Reinhard, Fink., Bernhard, M. K., Yves, Gensterblum., Alexandra, Amann-Hildenbrand., Apparent permeability of gas shales - Superposition of fluid-dynamic and poro-elastic effects, Fuel, 2017, 532-550, Doi:10.1016/j.fuel.2017.02.086 


\section{Appendix}

\section{Unit conversion}

For volume and mass of methane: $1 \frac{\mathrm{g}}{\mathrm{cm}^{3}} \times \frac{\mathrm{mol}}{16.04 \times \mathrm{g}} \times \frac{\mathrm{cm}^{3}}{1 \mathrm{E}^{-6} \times \mathrm{m}^{3}} \times 62344.140 \frac{\mathrm{mol}}{\mathrm{m}^{3}}$ For temperature conversion between Celsius and Kelvin: $\mathrm{K}=273.15+\mathrm{C}$. 